\title{
COMPARISON OF EFFICACY OF ACECLOFENAC AND IBUPROFEN AFTER SURGICAL REMOVAL OF IMPACTED THIRD MOLAR
}

\author{
Sumit Agarwal' ${ }^{1}$ Subhrajyoti Chattopadhyay2, Mohanchandra Mandal ${ }^{3}$ \\ ${ }^{1}$ Consultant Maxillofacial and Reconstructive Surgeon, "The Specialist's Clinic" (Dental \& Maxillofacial Centre) Department of \\ Dentistry, Siliguri, West Bengal. \\ ${ }^{2}$ Associate Professor, Department of Anaesthesiology, North Bengal Medical College, Sushrutanagar, West Bengal. \\ ${ }^{3}$ Associate Professor, Department of Anaesthesiology, North Bengal Medical College, Sushrutanagar, West Bengal.
}

\begin{abstract}
BACKGROUND

The removal of impacted mandibular third molar is one of the most frequently performed oral surgical procedure, which leads to severe pain and swelling owing to trauma and inflammation of soft tissue and bone. The quality of life after lower third molar surgery is affected three times more in patients with pain, swelling and trismus alone or in combinations. Postoperative pain after third molar surgery is often used as a model to test the efficacy of analgesics. Despite existence of several studies, no analgesics has won the certificate of excellence and the quest is still on to find out a better agent in this aspect.
\end{abstract}

\section{MATERIALS AND METHODS}

The present study was aimed at evaluating ibuprofen and aceclofenac, among 100 patients regarding the individual efficacies and to compare between the two drugs in reducing postoperative facial swelling, pain and trismus after removal of mandibular third molars. The patients were randomly divided into two groups to receive either ibuprofen $400 \mathrm{mg}$ (Group A, $\mathrm{n}=50$ ) or aceclofenac $100 \mathrm{mg}$ (Group B, $\mathrm{n}=50$ ), each drug $8^{\text {th }}$ hourly for three days postoperatively. Facial swelling, pain and mouth opening scores were recorded on the first, second, fifth and seventh postoperative days.

\section{RESULTS}

Both the drugs were found to be effective in controlling postoperative facial swelling, pain and mouth opening compared with their own baseline measurements. Relief of pain and trismus were found better in patients receiving ibuprofen (400 mg) compared with aceclofenac (100 mg), while control of facial swelling was found comparable between the groups.

\section{CONCLUSION}

The study concludes that both ibuprofen (400 mg) and aceclofenac (100 mg) are effective in controlling postoperative swelling, pain and trismus after surgical removal of impacted lower-third molars. Ibuprofen is better than aceclofenac in alleviation of pain and trismus. Control of facial swelling is comparable with the use of both drugs. A dose-response study and evaluation of different drug formulations of these molecules are warranted in such surgical setting in future.

\section{KEYWORDS}

Aceclofenac, Ibuprofen, Non-Steroidal Anti-Inflammatory Drugs, Postoperative Pain, Third Molar.

HOW TO CITE THIS ARTICLE: Agarwal S, Chattopadhyay S, Mandal M. Comparison of efficacy of aceclofenac and ibuprofen after surgical removal of impacted third molar. J. Evolution Med. Dent. Sci. 2017;6(21):1670-1677, DOI: 10.14260/Jemds/2017/368

\section{BACKGROUND}

The removal of impacted mandibular third molar is one of the most frequently performed oral surgical procedures carried out in daily dental practice. ${ }^{1}$ Swelling, pain and trismus are the most common postoperative complaints following Third Molar Surgery (TMS). Although the overall complication rate is low and most are minor in nature, these adverse events in any combination may be significant and can affect patients' quality of life in the days following surgery. ${ }^{2,3}$ Postoperative swelling or oedema is the result of inflammatory exudates. It is due to combined action of the inflammatory mediators that

Financial or Other, Competing Interest: None.

Submission 02-02-2017, Peer Review 27-02-2017,

Acceptance 04-03-2017, Published 13-03-2017.

Corresponding Author:

Dr. Subhrajyoti Chattopadhyay,

C/o. Mr. Satyajit Chakroborty,

Trinayani Apartment (2nd Floor),

Taltala, Arabinda Pally,

Siliguri-734006, West Bengal.

E-mail: drsubhra1972@gmail.com

DOI: $10.14260 /$ jemds $/ 2017 / 368$ induce vasodilatation and mediators that are responsible for increase in vascular permeability. ${ }^{4}$ Surgical trauma initiates the peripheral inflammatory reaction, which is the cause for postoperative pain. Postoperative swelling might contribute to the postoperative pain, because of increased tension in the tissues. $^{5}$

Better understanding about mechanisms of pain and inflammation has resulted in effective new measures of controlling postoperative swelling, pain and trismus. Pharmacologic strategies for minimising the clinical manifestations of surgical injury are logically directed at blocking the formation or inhibiting the effects of mediators of acute inflammation. ${ }^{6}$ Several types of medications such as antihistamines, Non-Steroidal Anti-Inflammatory Drugs (NSAIDs) and steroids have all been used to inhibit these postoperative sequelae. In most studies, NSAIDs have been used to control postoperative pain and steroids have been used to control swelling and trismus. ${ }^{6,7}$ The concept of using NSAIDs to control postoperative pain, facial swelling and trismus either as a single agent or in combination with other agents is becoming increasingly attractive, as more is learnt about their mechanisms of action. ${ }^{8}$ 
Ibuprofen is a propionic acid derivative with analgesic, anti-inflammatory and antipyretic properties. Aceclofenac is a member of phenyl acetic acid class of NSAIDs. It has analgesic and anti-inflammatory properties similar to those of indomethacin and diclofenac. Both ibuprofen and aceclofenac inhibit the cyclooxygenase enzyme system; hence, reduce the biosynthesis of prostaglandins. ${ }^{9}$ Additionally, ibuprofen inhibits migration and other function of leucocytes, whilst aceclofenac decreases intracellular concentration of free arachidonic acid in leucocytes. The pharmacological properties of NSAIDs could well have an impact on postoperative outcome following TMS. ${ }^{9}$

The efficacy of ibuprofen in postoperative dental pain is rather well established.5,9-13 However, there is paucity of studies regarding the analgesic efficacy of this drug in surgeries having severe pain of short duration associated with swelling such as TMS. There are a few studies comparing directly ibuprofen with aceclofenac in alleviation of pain following TMS and reported opposing views. 4,9,14

Hence, the present study was aimed at determining the individual efficacy of ibuprofen $400 \mathrm{mg}$ and tab. aceclofenac $100 \mathrm{mg}$ and also to compare the efficacy between the two drugs in terms of alleviation of postoperative pain, facial swelling and trismus after surgical removal of impacted mandibular third molar.

\section{MATERIALS AND METHODS}

This study was carried out on 100 patients who reported to the Specialist's Clinic (Dental and Maxillofacial Centre) for removal of mandibular third molars. Patients were enrolled for the study consecutively as and when they presented with their problems in this specialty care hospital.

The following were the criteria for selection of patients for the study. Patient with impacted mandibular 3 rd molar indicated for extraction were included. The patients with systemic comorbidity such as bleeding disorders, cardiovascular diseases, gastrointestinal lesions, diabetes mellitus, etc. were excluded. Likewise, patients having infection (systemic or dental) were not included. Patient not willing for extraction of impacted teeth were also not recruited for the study. Only those patients who met the inclusion and exclusion criteria were selected.

All the patients were informed with regard to the purpose of the study and effects of the drugs used. After the consent of the patient and case history, preoperative investigations and relevant findings were recorded using a pre-structured proforma.

\section{The following Details were recorded Preoperatively -}

- The tooth to be removed.

- The type of impaction.

- Preoperative facial swelling measurement.

- Duration of surgery (Incision to suturing).

- Inter-incisal distance in mm.

Materials used during Surgery and Postoperatively were-

- $\quad$ Standard impaction surgical kit.

- $5 \mathrm{~mL}, 1 \frac{1}{2}$ inch disposable syringe with 26 -gauge needle.

- $\quad$ Lignocaine solution with adrenaline $(1: 80,000)$.

- 3-0 silk suture material and metallic scale.

- Visual Analogue Scale (VAS), Vernier caliper.

- Tablet aceclofenac $100 \mathrm{mg}$ and tab. ibuprofen $400 \mathrm{mg}$.

\section{Surgical Procedure}

After routine blood and radiographic investigations, the patients were taken up for surgery. Once the patients were comfortably seated on the dental chair, face was prepared with povidone-iodine solution and draping was done. Intraoral preparation was done with povidone-iodine solution and normal saline irrigation and the surgery was carried out in the following manner.

Local anaesthesia was achieved through inferior alveolar nerve block, lingual nerve block and long buccal nerve block. A standard Terrance Ward's incision was placed. Using a periosteal elevator, the mucoperiosteal flap was reflected and the bone was exposed. The mucoperiosteal flap was then retracted using Austin's flap retractor.

Bone removal was carried out using a round and straight bur by guttering technique on the buccal and distal side, depending on the type of impaction. After adequate amount of bone removal, the tooth was delivered out of the socket by using an elevator. Whenever necessary, odontectomy was performed to facilitate the tooth removal. After the tooth was delivered out, the socket was irrigated with povidone-iodine solution and normal saline. Sharp bony margins were smoothened with a bone file and the socket debrided. Complete haemostasis was achieved before wound closure. Wound was closed with 3-0 black silk suture material using interrupted sutures. After the wound closure, a wet gauze pack was placed at the surgical site. Postoperative instructions were given and postoperative followup was advised.

Selected patients were randomly allocated into two groups, to receive either ibuprofen $400 \mathrm{mg}$ (Group $\mathrm{A}, \mathrm{n}=50$ ) or aceclofenac $100 \mathrm{mg}$ (Group B, $\mathrm{n}=50$ ), each drug $8^{\text {th }}$ hourly for three days after the surgical removal of mandibular third molars. All the patients were under standard antibiotic coverage for 5 days. Patients were followed up on the first, second, fifth and seventh postoperative days and data regarding facial swelling, pain and mouth opening scores (Inter-incisal distance) were recorded on those days.

Facial swelling was determined by recording facial size postoperatively and comparing it with pre-surgical baseline measurements. Facial swelling measurements were taken by marking 6 points on the face on the following facial landmarks; mandibular angle, tragus, lateral canthus of eye, alar base, lip commissure and pogonion. With the mandibular angle as the base point by using 3-0 silk suture to follow the contour of the face, linear distances to the other landmarks were noted. The sums of all measurements were taken as the facial size. Mouth opening was evaluated by measuring the maximum inter-incisal distance. It was recorded in millimetres by using Vernier caliper.

Pain was recorded objectively using 101 - point $(0-100 \mathrm{~mm})$ Visual Analogue Scale (VAS). The end points of the scale were 'no pain' and 'worst pain possible.' The mean from VAS were classified as none/no pain (0 - 10), mild pain $(11-30)$, moderate pain $(31-60)$ and severe pain $(61-100)$. In case of pain not reduced after the administration of study drug, patients were allowed to receive paracetamol $500 \mathrm{mg}$ as rescue analgesic and it was noted.

The data thus obtained was tabulated and subjected to statistical analysis (Student's paired and unpaired ' $t$ ' test) for the comparison of the efficacy of ibuprofen and aceclofenac after surgical removal of impacted third molar. The value of $\mathrm{P}$ $<0.05$ was considered as statistically significant. 


\section{RESULTS}

This study was aimed at evaluating the individual efficacy of ibuprofen and aceclofenac and comparison between the two drugs in reducing postoperative swelling, pain and trismus after surgical removal of mandibular third molars. All the patients complied the study protocol. Hence, data from 100 patients were available. Demographic parameters were comparable (Table 1).

\begin{tabular}{|c|c|c|c|}
\hline Parameters & $\begin{array}{c}\text { Ibuprofen } \\
\text { (n=50) }\end{array}$ & $\begin{array}{c}\text { Aceclofenac } \\
\text { (n=50) }\end{array}$ & P value \\
\hline Age (years) & $29.10 \pm 4.639$ & $28.64 \pm 6.845$ & 0.695 \\
\hline Weight (Kgs) & $59.02 \pm 7.032$ & $60.12 \pm 7.261$ & 0.443 \\
\hline Male/Female* & $27 / 23$ & $30 / 20$ & $0.686^{*}$ \\
\hline
\end{tabular}

Data presented as Mean \pm SD except marked ${ }^{*}$ which is represented as number of patients. Test applied independent sample t-test except the *marked, which is categorical data and tested with Pearson Chi-square and Fisher's Exact test. $\mathrm{P}<0.05$ is significant.

Table 1. Demographic Parameters

\begin{tabular}{|c|c|c|c|c|c|}
\hline Time of Assessment & Mean \pm SD & $\begin{array}{c}\text { Difference from Baseline } \\
\text { Measurement }\end{array}$ & $\begin{array}{c}\text { \% Increase from } \\
\text { Baseline }\end{array}$ & $\mathbf{t}$ & P value \\
\hline \multicolumn{6}{|c|}{ Ibuprofen Group $(\mathrm{n}=\mathbf{5 0})$} \\
\hline Pre-op (Baseline) & $445.6 \pm 11.7$ & - & - & - & - \\
\hline Post-op day 1 & $455.4 \pm 13.8$ & $9.9 \pm 7.2$ & 2.2 & 9.61 & $<0.001 \mathrm{HS}$ \\
\hline Post-op day 2 & $461.0 \pm 13.8$ & $15.4 \pm 20.3$ & 3.5 & 5.37 & $<0.001 \mathrm{HS}$ \\
\hline Post-op day 5 & $455.6 \pm 23.4$ & $10.6 \pm 20.2$ & 2.4 & 3.53 & $<0.01 \quad \mathrm{~S}$ \\
\hline Post-op day 7 & $449.8 \pm 19.1$ & $4.2 \pm 14.7$ & 0.9 & 2.04 & $<0.05$ \\
\hline \multicolumn{6}{|c|}{ Aceclofenac Group $(n=50)$} \\
\hline Pre-op (Baseline) & $449.2 \pm 9.2$ & - & - & - & - \\
\hline Post-op day 1 & $469.2 \pm 10.0$ & $20.4 \pm 10.4$ & 4.5 & 13.9 & $<0.001 \mathrm{HS}$ \\
\hline Post-op day 2 & $469.9 \pm 9.4$ & $20.7 \pm 7.6$ & 4.6 & 19.3 & $<0.001 \mathrm{HS}$ \\
\hline Post-op day 5 & $461.1 \pm 7.9$ & $11.9 \pm 6.0$ & 2.6 & 14.0 & $<0.001 \mathrm{HS}$ \\
\hline Post-op day 7 & $454.2 \pm 8.6$ & $5.0 \pm 4.9$ & 1.1 & 7.11 & $<0.001 \mathrm{HS}$ \\
\hline \multicolumn{6}{|c|}{ Intragroup analysis performed using paired student's ' $t$ ' test. $\mathrm{P}<0.05$ is significant; $\mathrm{S}$, Significant; HS, Highly Significant } \\
\hline \multicolumn{6}{|c|}{ Table 2. Facial Measurement (In $\mathrm{mm})$} \\
\hline
\end{tabular}

(Intergroup comparison between the magnitudes of changes in facial swelling from own group's preoperative baseline status).

\begin{tabular}{|c|c|c|c|c|}
\hline $\begin{array}{c}\text { Time of } \\
\text { Assessment }\end{array}$ & $\begin{array}{c}\text { Ibuprofen } \\
(\mathbf{n = 5 0})\end{array}$ & $\begin{array}{c}\text { Aceclofenac } \\
(\mathbf{n = 5 0}\end{array}$ & $\mathbf{t}$ & P value \\
\hline BL - D1 & $9.9 \pm 7.2$ & $20.4 \pm 10.4$ & 5.87 & $<0.01$ \\
\hline BL - D2 & $15.4 \pm 20.3$ & $20.7 \pm 7.6$ & 1.29 & $0.20 \mathrm{NS}$ \\
\hline BL - D5 & $10.6 \pm 20.2$ & $11.9 \pm 6.0$ & 0.44 & $0.66 \mathrm{NS}$ \\
\hline BL - D7 & $4.2 \pm 14.7$ & $5.0 \pm 4.9$ & 0.37 & $0.71 \mathrm{NS}$ \\
\hline Mean difference is presented. BL, baseline, D1, D2... day 1, \\
day 2, etc. P < 0.05 is significant; NS, Not significant \\
\hline \multicolumn{4}{|c|}{ Table 3. Comparison of Changes of Facial } \\
Measurement from Baseline, on Different Days \\
\hline
\end{tabular}

\section{Facial Swelling}

The baseline facial measurement in ibuprofen group increased by $2.2 \%$ on postoperative day one and by $3.5 \%$ on day two (Both $\mathrm{P}<0.001$ ). Gradually, there was reduction of facial swelling on $5^{\text {th }}$ and $7^{\text {th }}$ postoperative day. Overall, the mean difference was statistically significant. In aceclofenac group, the baseline facial measurement increased by $4.5 \%$ and $4.6 \%$ on postoperative day one and two $(\mathrm{P}<0.001)$ compared with preoperative measurement. There was gradual reduction in the facial swelling on day 5 and on day 7 (Table 2).

On intergroup analysis, it was found that the mean difference value (change from baseline) was statistically significant only for postoperative day one $(\mathrm{P}<0.001)$, while those on postoperative day two, day five and day seven were comparable (Table 3 and Figure 1).

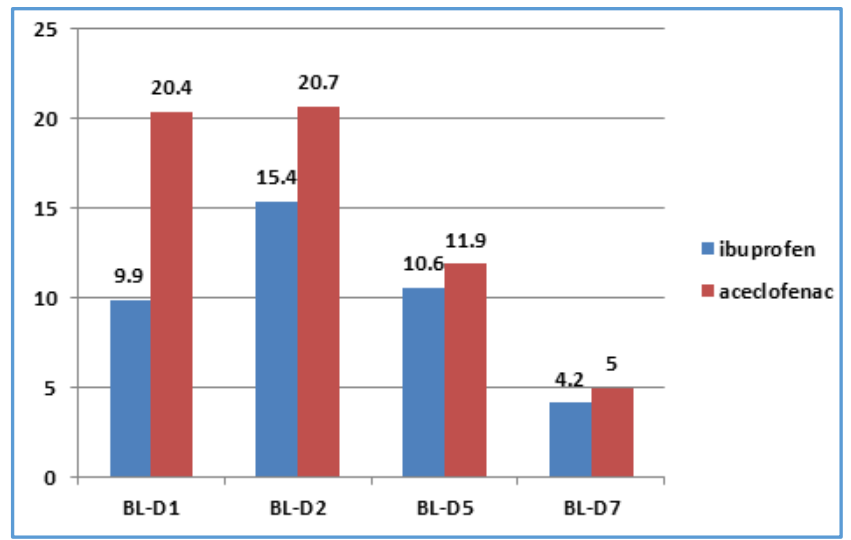

Figure 1. Differences of Facial Swelling from Baseline Measurement on Different Days

(Intergroup comparison between the magnitudes of changes in facial swelling from own group's preoperative baseline status). X-axis denotes time points. Y-axis denotes mean measurement in millimeters. BL, baseline; BL-D1, mean change of facial swelling on day 1 compared with baseline; BL-D2, mean change of facial swelling on day 2 compared with baseline, etc. 


\begin{tabular}{|c|c|c|c|c|c|}
\hline Time of Assessment & Mean \pm SD & Difference from Day 1 & \% Decrease from Baseline & $\mathbf{t}$ & P value \\
\hline \multicolumn{6}{|c|}{ Ibuprofen Group (n= 50) } \\
\hline Post-op day 1 & $56.2 \pm 17.1$ & - & - & - & - \\
\hline Post-op day 2 & $33.2 \pm 14.8$ & $23.4 \pm 17.1$ & 41 & 9.47 & $<0.001 \mathrm{HS}$ \\
\hline Post-op day 5 & $10.6 \pm 9.8$ & $45.6 \pm 18.4$ & 81 & 17.5 & $<0.001 \mathrm{HS}$ \\
\hline Post-op day 7 & $1.4 \pm 4.0$ & $54.8 \pm 12.5$ & 97 & 22.1 & $<0.001 \mathrm{HS}$ \\
\hline \multicolumn{6}{|c|}{ Aceclofenac Group $(n=50)$} \\
\hline Post-op day 1 & $68.4 \pm 14.9$ & - & - & - & - \\
\hline Post-op day 2 & $40.0 \pm 10.3$ & $28.4 \pm 14.1$ & 42 & 14.3 & $<0.001 \mathrm{HS}$ \\
\hline Post-op day 5 & $21.4 \pm 9.7$ & $47.0 \pm 16.4$ & 47 & 20.2 & $<0.001 \mathrm{HS}$ \\
\hline Post-op day 7 & $4.0 \pm 7.6$ & $64.4 \pm 7.6$ & 94 & 25.2 & $<0.001 \mathrm{HS}$ \\
\hline
\end{tabular}

\begin{tabular}{|c|c|c|c|c|c|}
\hline Time of Assessment & Ibuprofen (n = 50) & Aceclofenac (n = 50) & Mean Difference & t & P value \\
\hline Post-op day 1 & $56.2 \pm 17.1$ & $68.4 \pm 14.9$ & 12.2 & 3.80 & $<0.01$ \\
\hline Post-op day 2 & $33.2 \pm 14.8$ & $40.0 \pm 10.3$ & 6.8 & 2.67 & $<0.01$ \\
\hline Post-op day 5 & $10.6 \pm 9.8$ & $21.4 \pm 9.7$ & 10.8 & 5.54 & $<0.001 \mathrm{HS}$ \\
\hline Post-op day 7 & $1.4 \pm 4.0$ & $4.0 \pm 7.6$ & 2.6 & 2.14 & $<0.05$ \\
\hline Rescue analg. & $460.00 \pm 170.23$ & $450.00 \pm 208.25$ & 10.0 & 0.263 & P = 0.793 NS \\
\hline Unpaired student's 't' test for intergroup comparison. HS, highly significant; P < 0.05 is significant; S, significant; NS, \\
Not significant. Rescue Analg., total consumption of rescue analgesics (paracetamol) in mg \\
\hline
\end{tabular}

\section{Pain}

Evaluation of VAS in ibuprofen group showed a value in the range of 'moderate pain.' On the second postoperative day, the mean pain score again relates to 'moderate pain.' The difference of VAS reading $(23.4 \pm 17.1$; a $41 \%$ decrease when compared with first postoperative day) was significant. On fifth postoperative day, the mean pain score was $10.6 \pm 9.8$ which relates to 'mild pain' and decrease of VAS score by $45.6 \pm 18.4(81 \%$ decrease when compared with first postoperative day) was also significant. On seventh day, almost $97 \%$ reduction in pain was seen (Table 4, Figure 2).

In the aceclofenac group, pain on first postoperative day lies in the range of 'severe pain.' On second day, pain score relates to 'moderate pain.' The decrease of $28.4 \pm 14.1$ (42\%) on VAS was highly significant. On fifth postoperative day, the mean pain score was $21.4 \pm 9.7$ (Mild pain) and decrease of VAS score by $47.0 \pm 16.4$ (69\% decrease compared with first postoperative day) was also statistically significant. On seventh day, a reduction of $94 \%$ pain was seen compared to first postoperative day (Table 4, Figure 2).

Overall assessment of pain relief in both groups is reported in Table 5 and Figure 2. There was a significant variation between groups $(\mathrm{P}<0.001)$ with patients in the ibuprofen group having a better relief of pain compared with those in the aceclofenac group $(\mathrm{P}<0.001)$. Total dose of consumed rescue analgesics were comparable between the groups (Table 5).

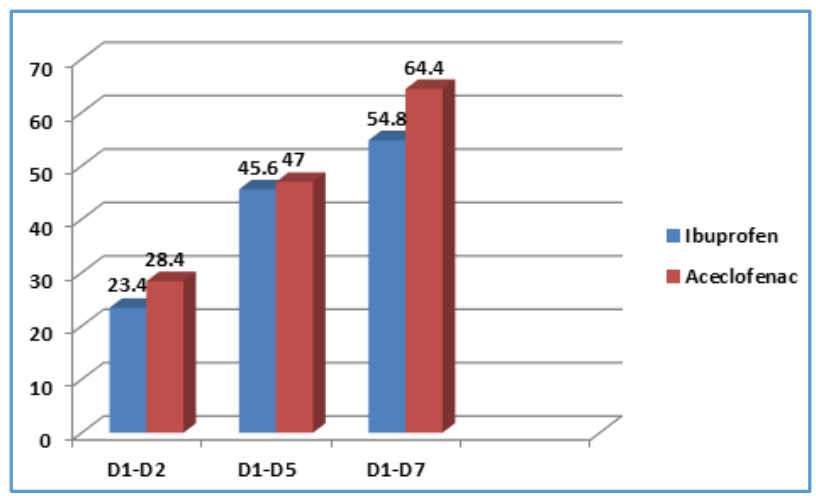

Figure 2. Comparison of Differences of

Pain Scores from Own Group's Day 1 Assessment

(Intergroup comparison between the magnitudes of changes in pain scores from own group's day one status). Xaxis denotes time points. Y-axis denotes mean change of VAS (in mm) compared with Day 1. D1 - D2 mean change of VAS on day 2 compared with day 1, D1 - D5 mean change of VAS on day 5 compared with day 1 , etc.

\begin{tabular}{|c|c|c|c|c|c|}
\hline Time of Assessment & Mean \pm SD & Difference from Baseline Measurement & \% Increase from Baseline & $\mathbf{t}$ & P value \\
\hline \multicolumn{6}{|c|}{ Ibuprofen Group $(\mathrm{n}=50)$} \\
\hline Pre-op (Baseline) & $42.4 \pm 3.2$ & - & - & - & - \\
\hline Post-op day 1 & $37.2 \pm 5.8$ & $5.2 \pm 4.5$ & 12.3 & 8.22 & $<0.001 \mathrm{HS}$ \\
\hline Post-op day 2 & $37.3 \pm 4.0$ & $5.1 \pm 3.5$ & 12.0 & 10.2 & $<0.001 \mathrm{HS}$ \\
\hline Post-op day 5 & 40.8. \pm 4.4 & $1.6 \pm 4.7$ & 3.8 & 2.31 & $<0.05 \mathrm{~S}$ \\
\hline Post-op day 7 & $42.8 \pm 2.6$ & -0.4 & 0.9 & 1.23 & $0.22 \mathrm{NS}$ \\
\hline \multicolumn{6}{|c|}{ Aceclofenac Group $(n=50)$} \\
\hline Pre-op (Baseline) & $42.7 \pm 2.5$ & - & - & & - \\
\hline Post-op day 1 & $34.5 \pm 3.8$ & $8.2 \pm 3.8$ & 19.2 & 15.1 & $<0.001 \mathrm{HS}$ \\
\hline Post-op day 2 & $34.9 \pm 2.8$ & $7.8 \pm 3.1$ & 18.3 & 17.7 & $<0.001 \mathrm{HS}$ \\
\hline Post-op day 5 & $39.3 \pm 1.9$ & $3.4 \pm 2.8$ & 8.0 & 9.85 & $<0.001 \mathrm{HS}$ \\
\hline Post-op day 7 & $41.9 \pm 1.9$ & $0.8 \pm 2.7$ & 1.9 & 2.23 & $<0.05 \mathrm{~S}$ \\
\hline \multicolumn{6}{|c|}{$\begin{array}{c}\text { Intragroup analysis performed using paired student's 't' test. P }<0.05 \text { is significant; } \\
\text { S, Significant; HS, Highly Significant; NS, Not Significant }\end{array}$} \\
\hline \multicolumn{6}{|c|}{ Table 6. Mouth Opening $(\mathrm{In} \mathrm{mm})$} \\
\hline
\end{tabular}




\begin{tabular}{|c|c|c|c|c|c|}
\hline Time of Assessment & Ibuprofen (n=50) & Aceclofenac (n=50) & Mean Difference & t & P-value \\
\hline Pre-op (Baseline) & $42.4 \pm 3.2$ & $42.7 \pm 2.5$ & 0.3 & 0.52 & $0.60 \mathrm{NS}$ \\
\hline Post-op day 1 & $37.2 \pm 5.8$ & $34.5 \pm 3.8$ & 2.7 & 2.75 & $<0.01 \mathrm{~S}$ \\
\hline Post-op day 2 & $37.3 \pm 4.0$ & $34.9 \pm 2.8$ & 2.4 & 3.48 & $<0.01 \mathrm{~S}$ \\
\hline Post-op day 5 & $40.8 . \pm 4.4$ & $39.3 \pm 1.9$ & 1.5 & 2.21 & $0.05 \mathrm{~S}$ \\
\hline Post-op day 7 & $42.8 \pm 2.6$ & $41.9 \pm 1.9$ & 0.9 & 1.98 & $0.05 \mathrm{~S}$ \\
\hline Unpaired student's 't' test for intergroup comparison. P < 0.05 is significant; S, significant; NS, Not Significant \\
\hline
\end{tabular}

\section{Mouth Opening}

In the ibuprofen group, the baseline measurement of mouth opening (c) decreased by $5.2 \pm 4.5 \mathrm{~mm}(12.3 \%)$ on day one and by $5.1 \pm 3.5 \mathrm{~mm}(12.0 \%)$ on postoperative day two, both being highly significant. The difference was $1.6 \pm 4.7 \mathrm{~mm}$ $(3.8 \%$ decrease) from preoperative measurement on postoperative day five $(\mathrm{P}<0.05)$ and increase of $0.4 \mathrm{~mm}$ $(0.9 \%)$ from baseline on $(\mathrm{P}=0.22)$ postoperative day seven. The magnitude of decrease in inter-incisal distance was found significant on intragroup analysis except on day 7. (Table 6, Figure 3), In the aceclofenac group, the baseline measurement was $42.7 \pm 2.5 \mathrm{~mm}$, which was comparable with that of ibuprofen group. A decrease in mouth opening by $8.2 \pm 3.8 \mathrm{~mm}(19.2 \%)$ was seen on day one and by $7.8 \pm 3.1$ $\mathrm{mm}(18.3 \%)$ on postoperative day two, both being highly significant. The difference from preoperative value (Baseline) was $3.4 \pm 2.8 \mathrm{~mm}(8.0 \%)$ on postoperative day five and $0.8 \pm$ $2.7 \mathrm{~mm} \mathrm{(1.9 \% )}$ on postoperative day seven, both significant on analysis. Thus, it appears that inter-incisal distance also improved significantly over different postoperative days within the aceclofenac group (Table 6, Figure 3).

The baseline value in both ibuprofen and aceclofenac group was almost similar. The mouth opening was significantly reduced at all times after surgery for the entire population. There was a marked decrease in the inter-incisal distance on the $1^{\text {st }}$ postoperative day with a mean difference of $2.7 \mathrm{~mm}$, which is significant. This was followed by a gradual increase in the inter-incisal distance in both the groups on postoperative day 2 with a mean difference of 3.48 $\mathrm{mm}$, which is again significant on analysis. On $5^{\text {th }}$ postoperative day, the mouth opening improved further in both the groups, the mean difference remained around 1.5 which is significant on intergroup analysis. On the $7^{\text {th }}$ postoperative day, the mouth opening reached almost baseline level and it is found comparable on intergroup analysis. So, on intergroup analysis, there was significant difference in inter-incisal distance between the groups except on day 1 and it was in favour of ibuprofen group (Table 7).

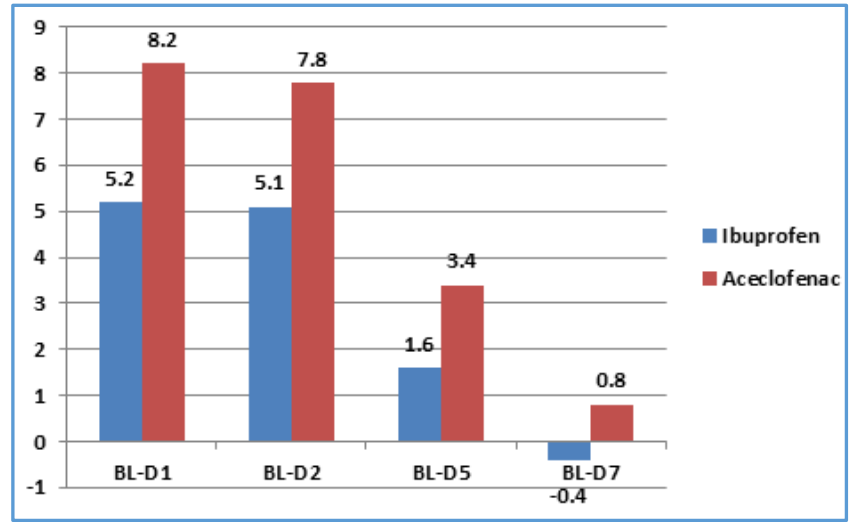

Figure 3. Comparison of Differences of Mouth Opening from Own Group's Day 1 Assessment
$\mathrm{X}$-axis denotes time points. Y-axis denotes change of mouth opening or inter-incisal distance (in $\mathrm{mm}$ ) compared with baseline (BL). BL-D1, change of mouth opening on day 1 compared with baseline; BL-D2, change of mouth opening on day 2 compared with baseline and so on.

\section{DISCUSSION}

Third Molar Surgery (TMS) involves trauma to soft tissue and bone resulting in postoperative inflammation, significant pain, swelling and dysfunction as direct and immediate consequences of the surgery. Incidence of severity of pain, trismus and swelling vary from patient to patient and do not appear to be related to the degree of impaction. ${ }^{15}$ Sensory nociception in the oral cavity is disproportionately greater than in most other areas of the body. ${ }^{16}$ Surgery of impacted lower third molars is known to cause more intense pain than any other oral surgical procedure. ${ }^{17}$ Pain after removal of impacted third molars is of short duration, usually accompanied by buccal swelling and trismus and reaches its maximum intensity at $4-6$ hours postoperatively. 4,9,18 There is predictable development of pain and inflammation in TMS, and usually it is performed in young patients without systemic pathology. Hence, the pain management in third molar surgery has become an efficient analgesic testing model. It allows researchers to test efficacy of analgesics and to make discrimination between weak and strong analgesics. ${ }^{19}$

The present study finds that patients of both groups had significant pain control on different postoperative days compared with the status of own group's first postoperative day. On intergroup analysis, patients in the ibuprofen group having a better relief of pain compared with those in the aceclofenac group. Facial swelling gradually decreased over postoperative days in both the groups and it was comparable between the two groups. Mouth opening improved over different postoperative days when compared to their own group's baseline. But when compared between the groups, the improvement was more satisfactory in patients receiving ibuprofen compared with aceclofenac.

Tissue injury from any source almost always evokes an inflammatory response. Inflammation is a normal immune response that initiates the healing process. Metabolites of arachidonic acid such as prostaglandins and leukotrienes play a major role in the inflammatory process by producing vasodilatation, increase in capillary permeability and promoting migration of leucocytes and macrophages to the sites of inflammation. ${ }^{4}$ Once initiated it may exceed normal physiologic limits and result in excessive swelling, pain and trismus. Pain generated by inflammation alert the subject about the presence of inflammation. This type of pain exerts a protective inhibitory influence on biomechanical activity and serves to monitor progress towards recovery. Hyperalgesia and swelling produced by inflammation affects daily life of 
patients. Owing to suppressive action on transudation process, corticosteroids have been advocated to limit postoperative oedema, although definitive recommendations supported with randomised control trials are a few to exist. Pain has been designated as the fifth vital sign in the recent past, thus putting importance on its assessment. Managing pain adequately is also of paramount importance, not only because it is humane but also for its legal importance. The International Association for the Study of Pain advocates that pain relief should be recognised as a fundamental human right. This agenda has been raised and being propagated with much importance for last two decades. ${ }^{20}$

In a study Osunde OD and Saheeb BD ${ }^{21}$ observed that age, gender and the level of surgical difficulty have no effect on pain and mouth opening limitation after TMS. In the present study, the demographic parameters were comparable and the study was not designed to detect such influence as well.

Ibuprofen (400) was compared with aceclofenac (100) regarding pain intensity, drug effectiveness, drug relief for the first 24 hours, swelling and trismus at immediate postoperative on $1^{\text {st }}, 3^{\text {rd }}$ and $7^{\text {th }}$ postoperative days. Pain relief was more profound in patients receiving ibuprofen as compared to aceclofenac. Ibuprofen has a marginal edge over aceclofenac. ${ }^{4}$ The improvements of the restriction of mouth opening and postoperative oedema have also been studied along with pain control. Thus, the overall recovery was found to be better with ibuprofen. ${ }^{4}$

In the treatment of postoperative pain following oral surgical procedures, ibuprofen has already been found to be more effective than aceclofenac ${ }^{9}$ and celecoxib. ${ }^{22}$ However, contrast reports do exist in the literature. In a recent study, aceclofenac $100 \mathrm{mg}$ has been reported to have better analgesic effect than ibuprofen $400 \mathrm{mg}$ in patients experiencing pain due to irreversible pulpitis. ${ }^{14}$ Aceclofenac has been reported to be more efficient in controlling pain when administered before surgery. ${ }^{15}$ Joshi et al $^{23}$ reported no significant difference in ibuprofen's efficacy for postoperative pain control in comparison with either diclofenac or acetaminophen plus codeine combination.

Well-established analgesic effect of ibuprofen was confirmed in Averbuch and Katzper's study.12 Efficacy of ibuprofen as an effective analgesic is already established during its comparison with other analgesics.5,9-13 Several studies have investigated analgesic dose-response of ibuprofen 200, 400, 600 and $800 \mathrm{mg}$ on postoperative pain management after TMS and it has been reported that ibuprofen $400 \mathrm{mg}$ provided the maximum pain relief and the largest durations of analgesic effect comparing to other doses. ${ }^{24,25}$ Hence, in the present study $400 \mathrm{mg}$ dose of ibuprofen was selected for its comparison with aceclofenac.

Aceclofenac is reported to be an effective and superior analgesic in the treatment of moderate-to-severe acute pain resulting from TMS with rapid onset, longer duration of action and better tolerability profile compared with diclofenac. ${ }^{26}$ Significant pain relief was observed in the immediate postoperative period of 8 hours in comparison to diclofenac sodium. ${ }^{27}$ Hence, in the present study we have chosen to test the efficacy of aceclofenac instead of diclofenac.

Assessment of facial swelling is technically more troublesome. It requires part-wise measurements based on several anatomical landmarks, then adding up, etc. to get a single reading. On the other hand assessment of pain is simple and quick with the use of VAS, but relies heavily on patient's cooperation and interpretation of pain. In this present study, VAS was used to assess pain and Vernier caliper was used to measure mouth opening.

Quantitative assessment of swelling represents a major difficulty. Post-surgical facial oedema is difficult to quantify accurately, since it requires a three-dimensional measurement with an irregular, convex surface and can manifest itself internally as well as externally. Over the years, various techniques have been tried to measure oedema in an objective way. Most of which are indirect assessment of the altered contours of skin surface. Measurement tools mentioned in the literature have included standardised stereo-radiographic or photographic measurements, computerised tomography, linear measurement, Vernier calipers to measure cheek-girth, modified face-bow devices, ultrasonography, facial plethysmographs or various other means of taking direct facial measurements. ${ }^{28}$ No technique has been proved to be superior or more accurate in analysing swelling. In the present study measurement of different facial landmarks was done using 3-0 silk as a low-cost, feasible and reliable technique for the assessment of facial swelling.

Pain is not simply determined by the intensity of nociceptive stimulation, but also depends on psychological factors such as the emotional and motivational state. The 'mind set' may alter an individual's ability to tolerate pain. ${ }^{29}$ Anxiety levels have been shown to predict pain severity and pain behaviour in acute and chronic pain patients. ${ }^{30}$ Fear, anxiety and apprehension serve to heighten an individual's painful experience. Elimination of these aspects either by pharmacological or psychological methods greatly increases a person's ability to tolerate noxious stimuli, most probably by activating descending control mechanisms.

Both paracetamol and ibuprofen are commonly used for the relief of pain following TMS. Fixed dose combination of diclofenac and paracetamol offer superior analgesia compared with ibuprofen in the management of acute postoperative pain following TMS. ${ }^{31}$ In 2010, paracetamol and ibuprofen combination in the same tablet was licensed for use in the United Kingdom. In a systematic review, 32 ibuprofen was found to be more effective than paracetamol at all doses studied in that review. Based on limited evidence, the review concludes that the combination of ibuprofen and paracetamol appeared to be no more effective than the single drugs at two hours after surgery, but more effective than the individual drugs when assessed at six hours after surgery. ${ }^{32}$

In another systematic review,33 some generalised comments are made as follows. The effect of single-dose analgesics in participants with moderate or severe acute pain was from $70 \%$ achieving good pain relief with the best drug to about $30 \%$ with the worst drug. The period of pain relief also varied from about 2 to 20 hours. No drug produced high levels of pain relief in all participants. The authors ${ }^{33}$ commented that it is not surprising if some analgesics do not work at all for some patients. Alternative analgesic drugs or procedures should be kept for ready use. Acute pain management is often part of complex interactions between patient, condition and desired outcome. These observations may partly explain the need for provision of rescue analgesics. Also it helps in understanding the reported higher success rates of different fixed-dose combinations in the same tablet or simultaneous use of second analgesic 
preparation. In the present study, paracetamol has been used as rescue analgesics in case of failure of analgesia of study drugs.

The need for good pain relief is of paramount importance for the clinician as well as the patient as under-treatment of pain in patients can have serious consequences including physiological complications, psychological impairments and overall decrease in quality of life. ${ }^{29,30}$

The present study bears some lacunae. The analgesics were administered after the surgery and the pre-emptive or preventive effect was not assessed. The anxiety level of patients was not assessed. Moreover, the magnitude of facial swelling was also not assessed using any other sophisticated way due to feasibility ground. These remain the future scope.

\section{CONCLUSION}

The study concludes that both ibuprofen and aceclofenac appears to be effective in terms of controlling postoperative pain, facial swelling and trismus after surgical removal of impacted lower-third molars. The use of ibuprofen (400 mg) results in better alleviation of postoperative pain and trismus compared with aceclofenac $(100 \mathrm{mg})$. Comparable reduction in facial swelling is observed with both the drugs. However, a dose-response study and further evaluation regarding comparative efficacy of these drugs, especially with different drug formulations are warranted in the field of third molar surgery.

\section{REFERENCES}

[1] Silvestri AR, Singh I. The unresolved problem of the third molar: would people be better off without it? J Am Dent Assoc 2003;134(4):450-5.

[2] Barden J, Edwards JE, McQuay HJ, et al. Pain and analgesic response after third molar extraction and other postsurgical pain. Pain 2004;107(1-2):86-90.

[3] Bamgbose BO, Akinwande JA, Adeyemo WL, et al. Prospective, randomized, open label, pilot clinical trial comparing the effects of dexamethasone coadministered with diclofenac potassium or acetaminophen and diclofenac potassium monotherapy after third molar extraction in adults. Curr Ther Res Clin Exp 2006;67(4):229-40.

[4] Jain N, Maria A. Randomized double blind comparative study on the efficacy of ibuprofen and aceclofenac in controlling post-operative sequelae after third molar surgery. J Maxillofac Oral Surg 2011;10(2):118-22.

[5] Jatin K, Lata J, Singh TPA. Comparative study on the efficacy of rofecoxib and ibuprofen in controlling postoperative sequelae following third molar surgeries. J Maxillofac 0 Surg 2007;6(1):17-21.

[6] Troullos ES, Hargreaves KM, Butler DP, et al. Comparison of nonsteroidal anti-inflammatory drugs, ibuprofen and flurbiprofen, with methylprednisolone and placebo for acute pain, swelling, and trismus. J Oral Maxillofac Surg 1990;48(9):945-52.

[7] Geresma L, Baker L. Use of corticosteroids in oral surgery. J Oral Maxillofac Surg 1992;50(3):270-7.

[8] Michael GS, Michael AH. Preoperative nonsteroidal anti-inflammatory agents: review of the literature. Oral Surg Oral Med Oral Pathol Oral Radiol Endod 2004;98(2):146-52.
[9] Seymour RA, Frame J, Negus TW, et al. The comparative efficacy of aceclofenac and ibuprofen in postoperative pain after third molar surgery. Br J Oral Maxillofac Surg 1998;36(5):375-9.

[10] Vogel IR, Desjardins JP, Major VK. Comparison of presurgical and immediate postsurgical ibuprofen on postoperative periodontal pain. J Periodontol 1992;63(11):914-8.

[11] McQuay CD, Guest PG, Robson S, et al. A multiple dose comparison of ibuprofen and dihydrocodeine after third molar surgery. Br J Oral Maxillofac Surg 1993;31(2):95-100.

[12] Averbuch M, Katzper M. Severity of baseline pain and degree of analgesia in the third molar post-extraction dental pain model. Anesth Analg 2003;97(1):163-7.

[13] Morse Z, Tump A, Kevelham E. Ibuprofen as a preemptive analgesic is as effective as rofecoxib for mandibular third molar surgery. Odontology 2006;94(1):59-63.

[14] Pavithra P, Dhanraj M, Sekhar P. Analgesic Effectiveness of ibuprofen and aceclofenac in the management of acute pulpitis-a randomized double blind trial. Int J Pharm Sci Rev Res 2015;35(2):70-4.

[15] Lima PPV, Fontanella V. Analgesic efficacy of aceclofenac after surgical extraction of impacted lower third molars. Int J Oral Maxillofac Surg 2006;35(6):518-21.

[16] Fletcher MC, Spera JF. Pre-emptive and postoperative analgesia for dentoalveolar surgery. Oral Maxillofacial Surg Clin North Am 2002;14(2):137-51.

[17] Mony D, Kulkarni D, Shetty L. Comparative evaluation of preemptive analgesic effect of injected intramuscular diclofenac and ketorolac after third molar surgery-a randomized controlled trial. J Clin Diagn Res 2016;10(6):ZC102-6.

[18] Chitalangia P, Hemavathi KB, Narad C, et al. Comparative effcacy of aceclofenac and ibubrufen in post-operative pain after lower third molar surgery-a clinical study. Ind Jr Contemp Dent 2013;1:88-92.

[19] Mehlisch DR. The efficacy of combination analgesic therapy in relieving dental pain. J Am Dent Assoc 2002;133(7):861-71.

[20] International Pain Summit of The International Association For The Study Of Pain. Declaration of montréal: declaration that access to pain management is a fundamental human right. J Pain Palliat Care Pharmacother 2011;25(1):29-31.

[21] Osunde OD, Saheeb BD. Effect of age, sex and level of surgical difficulty on inflammatory complications after third molar surgery. J Maxillofac Oral Surg 2015;14(1):7-12.

[22] Doyle G, Jayawardena S, Ashraf E, et al. Efficacy and tolerability of nonprescription ibuprofen versus celecoxib for dental pain. J Clin Pharmacol 2002;42(8):912-9.

[23] Joshi A, Parara E, Macfarlane TV. A double-blind randomised controlled clinical trial of the effect of preoperative ibuprofen, diclofenac, paracetamol with codeine and placebo tablets for relief of postoperative pain after removal of impacted third molars. Br J Oral Maxillofac Surg 2004;42(4):299-306. 
[24] Schou S, Nielsen H, Nattestad A, et al. Analgesic doseresponse relationship of ibuprofen 50,100, 200 and $400 \mathrm{mg}$ after surgical removal of third molars: a single dose, randomised, placebo-controlled, and doubleblind study of 304 patients. Clin Pharmacol 1998;38(5):447-54.

[25] Derry S, Derry CJ, Moore RA. Single dose oral ibuprofen plus oxycodone for acute postoperative pain in adults. Cochrane Database Syst Rev 2013;26(6):CD010289.

[26] Chunduri NS, Kollu T, Goteki VR, et al. Efficacy of aceclofenac and diclofenac sodium for relief of postoperative pain after third molar surgery: a randomised open label comparative study. J Pharmacol Pharmacother 2013;4(2):144-5.

[27] Jyothsna K, Deshpande N, Vijayalakshmi G. Efficacy and safety of diclofenac sodium and aceclofenac in controlling post extraction dental pain: a randomised open label comparative study. J Pharmacol Toxicol 2011:41-7.

[28] Ebert RH. The experimental approach to inflammation. In: Zweifach B. The inflammatory process. New York: Academic press 1965:1-2.
[29] Rhudy JL, Meagher MW. Fear and anxiety: divergent effects on human pain thresholds. Pain 2000;84(1):6575.

[30] Ploghaus A, Narain C, Beckmann CF, et al. Exacerbation of pain by anxiety is associated with activity in a hippocampal network. J Neurosci 2001;21(24):9896903.

[31] Dhusia HL, Bhange PD, Sonar MD, et al. Combination of diclofenac with paracetamol offer better pain relief than ibuprofen alone in impacted third molar extraction: a randomized controlled trial. Int J Res Med 2013;2(2):109-14.

[32] Bailey E, Worthington HV, van Wijk A, et al. Ibuprofen and/or paracetamol (acetaminophen) for pain relief after surgical removal of lower wisdom teeth. Cochrane Database Syst Rev 2013;12:CD004624.

[33] Moore RA, Derry S, McQuay HJ, et al. Single dose oral analgesics for acute postoperative pain in adults. Cochrane Database Syst Rev 2011;9:CD008659. 